\title{
Clinical and Radiographical Measurements of Supraeruption and Occlusal Interferences in Unopposed Posterior Teeth
}

\author{
Mohammed M Al Moaleem ${ }^{1}$, Amit Porwal ${ }^{2}$, Mohammed A Qahhar ${ }^{3}$, Feras A Al Qatarneh ${ }^{4}$, Seham A Areeshi ${ }^{5}$, \\ Mohammad BF Aldossary ${ }^{6}$
}

\begin{abstract}
Aims and objectives: This study compared the supraeruption of teeth for study casts (SCs) and panoramic radiographs (PRs) and its relation to tooth type, arch, facial sides, presence of occlusal interferences, and type of tooth movements.

Materials and methods: A total of 65 patients with their SCs and PRs were recruited. Supraerupted tooth type, arches, sides involved, and the presence of occlusal interferences were recorded. The SCs for supraerupted teeth were photographed, and supraeruption from PRs was recorded from the patients' files. The values were transferred to a software program and assessed.

Results: The highest frequency was observed among the younger-age group and molars in both arches. Working side (WS) and retruded cuspal position (RCP) interferences were recorded the highest. Supraeruption values of $0.7-1.2 \mathrm{~mm}$ accounted for $47.5 \%$ (38) of the total. Tilting and tipping of teeth were the highest, followed by buccolingual displacement. Kappa tests showed good intraexaminer reliability and Bland-Altman plot showed $95 \%$ confidence interval band.

Conclusions: No significant differences were observed in the supraeruption values between the type of tooth among different subgroups of SCs and PRs. Significant differences were recorded between the types and sites of teeth, with a higher ratio observed in molar teeth, mandibular arch, and young age group. RCP and WS were the most recorded occlusal interferences and buccolingual displacement, and tilting and tipping were the most noticeable occlusal tooth movements.

Clinical significance: Diagnosis and measurements of supraeruption are essential, useful, and significant steps before treatments for replacement of missing tooth/teeth as well as corrections of occlusal interferences during different mandibular movements.

Keywords: Occlusal interferences, Overeruption, Panoramic radiograph, Study casts, Supraeruption.

The Journal of Contemporary Dental Practice (2021): 10.5005/jp-journals-10024-3143
\end{abstract}

\section{INTRODUCTION}

Supraeruption is defined as a measure of excess tooth movement starting from the cusp tip to the carve passing over the canine, premolars, and molars. ' Supraeruption of the posterior teeth is one of the common clinical findings in daily dental practice. Postponed replacement of extracting teeth often leads to extrusion of the opposing tooth into the edentulous space, which results in masticatory insufficiency and temporomandibular joint (TMJ) disorders. ${ }^{2-4}$ When a fixed or removable prosthesis is planned on the opposing edentulous arch, re-establishing a functional posterior occlusion requires a comprehensive dental treatment plan. 5,6

The first permanent molars in either the maxillary ${ }^{7-9}$ or mandibular arch ${ }^{10-12}$ are the most commonly missing posterior teeth, followed by the premolars in the maxillary arch. ${ }^{13}$ Other studies $^{5,14}$ concluded that mandibular posterior teeth are more likely to be extracted than maxillary posterior teeth, and with the increase in age, posterior teeth are more likely to be extracted and lost bilaterally.

Supraeruption of teeth can be classified based on the extent of supraeruption from the occlusal plane into mild (supraerupted tooth extends between $0.1 \mathrm{~mm}$ and $1.5 \mathrm{~mm})$, moderate $(1.6-3.5 \mathrm{~mm})$, and severe (exceeds $3.5 \mathrm{~mm}$ ). ${ }^{1,15,16}$ Based on the amount of reduction required for supraerupted tooth, it can also be classified into conservative, semiconservative and nonconservative. ${ }^{2}$

A group of studies ${ }^{5,17-19}$ investigated the type and extent of supraeruption and tooth movements associated with posterior teeth without their antagonist. These studies also recorded any

\footnotetext{
1,2 Department of Prosthetic Dental Science, College of Dentistry, Jazan University, Jazan, Saudi Arabia

${ }^{3}$ Altuwal General Hospital, Ministry of Health, Jazan, Saudi Arabia

${ }^{4}$ Royal Medical Services, Aman, Jordan

${ }^{5,6}$ College of Dentistry, Jazan University, Jazan, Saudi Arabia
}

Corresponding Author: Mohammed M Al Moaleem, Department of Prosthetic Dental Science, College of Dentistry, Jazan University, Jazan, Saudi Arabia, e-mail: drmoaleem2014@gmail.com

How to cite this article: Al Moaleem MM, Porwal A, Qahhar MA, et al. Clinical and Radiographical Measurements of Supraeruption and Occlusal Interferences in Unopposed Posterior Teeth. J Contemp Dent Pract 2021;22(7):784-792.

Source of support: Nil

Conflict of interest: None

relationship between the supraeruption of teeth and oral or patient factors. In addition, they investigated the relationship of tooth positional interferences following posterior tooth loss during different mandibular arch movements.

Craddock et al. ${ }^{5}$ stated that the average amount of supraerupted teeth ranges from 1.68 to $3.99 \mathrm{~mm}$ of the teeth without opposition, with values of 1.03 and $1.91 \mathrm{~mm}$ recorded for the mandibular and maxillary arches, respectively. Kiliaridis et al. ${ }^{20}$ registered that $24 \%$ of unopposed teeth had more than $2 \mathrm{~mm}$ overeruption among $82 \%$ of the examined subjects with unopposed teeth. Another study 
quantified the occlusal change of unopposed teeth to be mostly within the border of $2 \mathrm{~mm}^{19}$

No previous study in Saudi Arabia or Jazan City had investigated supraeruption and the associated complications. The present study aimed to measure and compare the amount of supraeruption of teeth from study casts (SCs) and panoramic radiographs (PRs) and its relation to tooth type, arch, sides, and the causes of tooth extraction among subpopulations in Jazan City. The presence of occlusal interferences during different mandibular movements and the type of tooth movements at the adjacent or opposite arch of the extraction site were also recorded and detected. The study hypotheses were as follows: No differences exist in the values of supraerupted teeth from SCs or PRs. No association exists between the presence of an occlusal interference and supraeruption of unopposed posterior teeth. No tilting or drifting in tooth position occurs following the loss/extraction of an antagonist in posterior teeth. No occlusal interferences are associated with unopposed posterior teeth.

\section{Materials and Methods}

\section{Study Design}

Eighty subjects were recruited from dental clinics, College of Dentistry, Jazan University in this cross-sectional clinical and radiographic comparative study. All the patients were recruited from the pool of the patients who reported for treatment to the college. The supraerupted teeth selected from these subjects were unopposed posterior teeth in the maxillary or mandibular arches. Ethical clearance was obtained from the ethical committee, college of Dentistry, Jazan University (CODJU-19211). Details of the study were discussed with the subjects before the clinical examination and collection of data, and written consent was obtained. This study has been carried out in accordance with the guidelines of the World Medical Association Declaration of Helsinki.

\section{Study Samples and Criteria}

According to the number of patients attended for prosthodontic treatments in the previous 5 years. The sample size of about 80 participants was verified based on a G*Power software (http:// www.gpower.hhu.de/en.html) with the self-assurance amount altered at $85 \%$, power adjusted at $80 \%$, and a reasonable outcome amount. This study included patients who attended dental clinics from December 2019 to February 2020 and their clinical and radio graphic examinations were performed. The inclusion criteria for the participants were aged 18 years old or above and the presence of anterior and posterior vertical stops with at least one supraerupted posterior maxillary/mandibular tooth. The extracted teeth should have been in the posterior areas of any arch and had been extracted in the past 3 years at least. The subjects should have not had received any previous prosthodontic nor orthodontic dental treatments.

\section{Clinical and Radiographic Evaluation}

The first part of the clinical study was related to the collection of personal and demographic data, such as different age groups (18-32, 33-47,and $\geq 48$ years), years passed since extraction (3-5 and $\geq 5$ years), and the cause of tooth loss (periodontal disease, dental caries, failed root canal treatment (RCT) and others such as pathological or dental trauma). A tooth was classified as requiring extraction due to dental caries when the crown had been destroyed by caries and was nonrestorable. However, extraction due to periodontal disease was considered if it satisfied the eighth criterion of Russell's periodontal index, i.e., the presence of considerable mobility in accordance with Miller's mobility index (1995). ${ }^{21,22}$ A tooth with the previous RCT can be considered a failed RCT when retreatment cannot be performed due to any reasons/under any existing condition. ${ }^{23}$

The second part included the registration of involved supraerupted teeth (premolars and molars), side (right or left), and arch (maxillary or mandibular). Supraeruption is defined as the movement of a tooth or teeth above the normal occlusal plane. ${ }^{24}$ The presence or absence of occlusal interferences during different mandibular movements, such as retruded cuspal position $(\mathrm{RCP})$, protrusive (PRO), working side (WS), and non-WS(NWS) interferences, was assessed by using an articulating paper and recorded as mentioned in the work of Craddock and Youngson. ${ }^{1}$ An articulating paper (red and blue) measuring 80 microns was held by a Millers' forceps and used to detect the presence or absence of occlusal interferences.

The third part involved the design of occlusal analysis of the SCs of each participant. All the SCs were prepared from an alginate dust-free impression material (ZETALGIN CHROMATIC, Zhermack, Germany). The impressions were poured with improved die stone type IV (DURGUIX, Protechno, Advanced Products for Dental Labs, Vilamalla, Girona, Spain) to construct SCs with a standard base length (Fig. 1A) as prescribed by Craddock et al. ${ }^{5}$

All SCs involvingthe supraerupted tooth/teeth were mounted on a table at a $25 \mathrm{~cm}$ distance from the camera and on the occlusal surface positioned parallel to the table top. A digital camera (Cyber-shot ${ }^{\circledR}$ S750 Digital Camera DSCS750, Sony, Japan) with 18.1 megapixels was mounted on a tripod stand (Benro Tripod T-600 Ex, Copyright Beniro Industrial Inc., China) perpendicular to the long axis of the axial line of the supraerupted tooth, with the occlusal surface positioned parallel to the table top (Fig. 1B). All the captured photographs were transferred to a personal computer. Later, a line was drawn passing from the buccal tips of the last tooth to the canine in the supraerupted $\operatorname{arch}^{1}$ by AutoCAD 2000 program (Pinnacle System, Middlesex, UK). Finally, the amount of tooth structure outside or lower than this line was recorded $(\mathrm{mm})$ as the amount of supraeruption (Fig. 1B) by atrained investigator (M.M).

The supraeruption values were measured, recorded, and divided into three modified scales $(0.1-0.6,0.7-1.2$, and $>1.3 \mathrm{~mm})$ in accordance with previous studies. ${ }^{1,5}$ Then the status of supraerupted and opposing/adjacent teeth or arches wasregistered as "yes" or "no" for the following conditions: no occlusal changes, buccolingual displacement of supraerupted teeth, presence of tilting, rotating, drifting, or tipping in mesial or distal of edentulous areas, presence of occlusal wear, and presence of open contact. ${ }^{1,17}$

The fourth part concerned the measurements of the extent of supraeruptionin the teeth of participants based on their PR files. The panoramic digital radiograph machine used in this study was tomography x-ray system model PaX-Flex3D (Germany) operated at $30 \%$ magnification. Supraeruption was calculated by drawing a straight line joining the tips of buccal cusps between the canine and the last tooth of arch on the supraerupted teeth side. The amount of supraeruption was calculated as the Figure $1 \mathrm{C}$ as mentioned by Kim et al. ${ }^{25}$

\section{Data Analysis}

Data were collected and summarized in an Excel sheet (Office 2010) on acomputer. The results of descriptive statistical analysis were represented as mean, frequency, percentages, and standard deviation (SD) using Statistical Package for Social Science software 

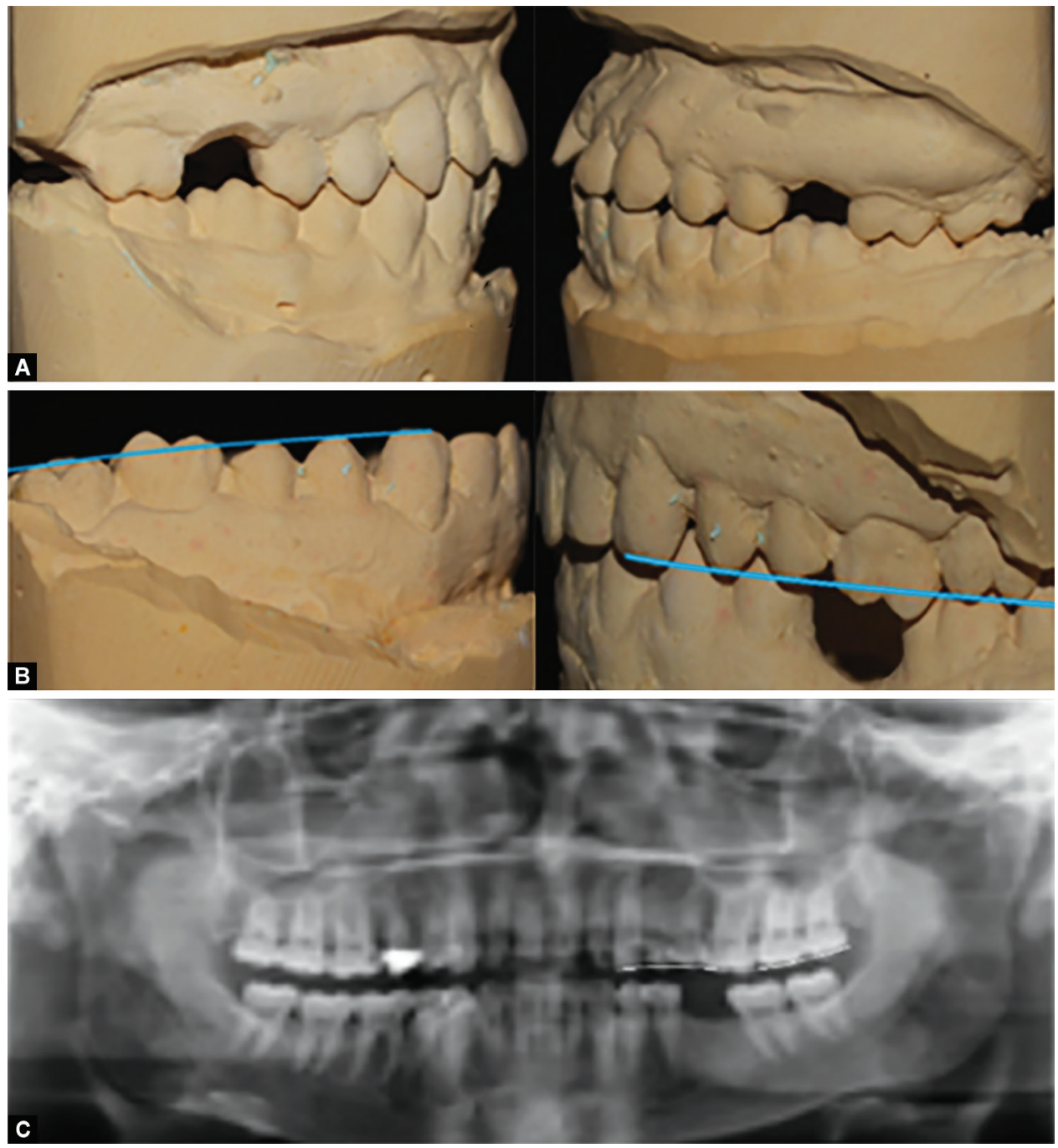

Figs 1A to C: (A) SCs after trimming; (B) Measurements of supraerupted tooth compared with adjacent teeth from SC; (C) Measurements of supraeruption from PR

program version 21 (Chicago, Illinois, USA). Thecomparisons and association between different age groups and types of supraerupted tooth variables with the clinical, SC, and PR findings were determined using Chi-square (Fisher's exact) test with $p \leq 0.05$ considered as significant. The Kappa test score for nominal data was used to detect agreements in the presence or absence of occlusal interferences during different mandibular movements. In addition, intraexaminer reliability by Bland-Altman plot 7 for continuous data was applied to assess and demonstrate the degree of agreement between two samples, and supraeruption measurements ( $\mathrm{SC}$ and $\mathrm{PR}$ ) were carried out by the same examiner on different occasions.

\section{Results}

A total of 80 supraerupted teeth in the posterior area of both arches was included in this in vitro comparative study. The values of supraeruption $(\mathrm{mm})$ from the PRs presented in this section were gained after a 30\% magnification reduction. Table 1 shows the descriptive statistics of the subjects, including the age groups, the number of years since tooth loss, and values of supraerupted teeth $(\mathrm{mm})$ from the SCs and PRs, included in this study (Table 1).

Table 2 shows the association between supraeruption and different age groups with other parameters. Dental caries was the most common cause of tooth loss among younger-age groups, accounting for almost 21 supraerupted teeth (38.9\%) in the 18-32-year-old and 20 supraerupted teeth (37\%) in 33-47-year-old subjects/subgroups. With the increase in age, periodontal diseases became the most common cause of tooth loss (50\%), showing a significant difference at $p=0.039$. A highly significant difference was observed in the status of supraerupted teeth and the opposing arches with the different age groups with $p>0.001$. Buccolingual displacement of supraerupted teeth (19-23.8\%]) and tilting or tipping in mesial or distal of edentulous are as [20(25.0\%)] were the most significant parameters among the subgroups. No significant differences were noted between the different age groups and other variables.

Similarly, a highly significant difference was recorded between the arch and tooth type with $p>0.001$, in which molars in both arches accounted for the highest numbers and included 23 (28.8\%) and 27 
Table 1: Descriptive demographic data of subjects and supraeruption $(\mathrm{mm})$ from SC and PR $(n=80)$

\begin{tabular}{|c|c|c|c|c|c|}
\hline Variable & Subgroups & Number (n) & Percentage & Mean & Standard deviation \\
\hline \multirow[t]{3}{*}{ Age groups(years) } & $18-32$ & 35 & 43.8 & 36.988 & 11.480 \\
\hline & $33-47$ & 28 & 35.0 & & \\
\hline & $>47$ & 17 & 21.2 & & \\
\hline \multirow[t]{2}{*}{ Years since toothloss } & $3-5$ years & 58 & 72.5 & 4.350 & 1.736 \\
\hline & $>5$ years & 22 & 27.5 & & \\
\hline \multirow[t]{4}{*}{ Supraeruptionfrom SC } & No supraeruption & 6 & 7.5 & 0.7162 & 0.466 \\
\hline & $0.1-0.6 \mathrm{~mm}$ & 27 & 33.7 & & \\
\hline & $0.7-1.2 \mathrm{~mm}$ & 38 & 47.5 & & \\
\hline & $>1.3 \mathrm{~mm}$ & 9 & 11.3 & & \\
\hline \multirow[t]{4}{*}{ Supraeruption in $\mathrm{mm}$ from $\mathrm{PR}$} & No supraeruption & 4 & 5.0 & 0.7250 & 0.464 \\
\hline & $0.1-0.6 \mathrm{~mm}$ & 29 & 36.3 & & \\
\hline & $0.7-1.2 \mathrm{~mm}$ & 38 & 47.5 & & \\
\hline & $>1.3 \mathrm{~mm}$ & 9 & 11.2 & & \\
\hline
\end{tabular}

Table 2: Association between the frequency and \% of variables in relation to different age groups [Chi-square or Fisher's exact test $(n=80)$ ]

\begin{tabular}{|c|c|c|c|c|c|c|}
\hline Variable & Age groups & $18-32 \mathrm{~N} \%$ & $33-47 N \%$ & $>47 N \%$ & Total N\% & $p$ values \\
\hline \multirow[t]{2}{*}{ Years since toothloss } & $3-5$ year & $27(46.6)$ & $17(29.3)$ & $14(24.1)$ & $58(72.5)$ & 1.54 \\
\hline & $>5$ years & $8(36.3)$ & $11(50.0)$ & $3(13.7)$ & $22(27.5)$ & \\
\hline \multirow[t]{4}{*}{ Causes of tooth loss } & Periodontal disease & $0.00(00)$ & $3(50.0)$ & $3(50.0)$ & $6(7.5)$ & $0.039^{*}$ \\
\hline & Dental caries & $21(38.9)$ & $20(37.0)$ & $13(24.1)$ & $54(67.5)$ & \\
\hline & Failed RCT & $10(71.4)$ & $3(21.4)$ & $1(7.1)$ & $14(17.5)$ & \\
\hline & Others & $4(66.7)$ & $2(33.3)$ & $0.00(00)$ & $6(7.5)$ & \\
\hline \multirow[t]{4}{*}{ Supraerupted tooth/teeth } & Maxillary premolars & $5(41.7)$ & $3(25.0)$ & $4(33.3)$ & $12(15.0)$ & 0.94 \\
\hline & Maxillary molars & $11(47.8)$ & $6(26.1)$ & $6(26.1)$ & $23(28.8)$ & \\
\hline & Mandibular molars & $4(22.2)$ & $12(66.7)$ & $2(11.1)$ & $18(22.5)$ & \\
\hline & Mandibular molars & $15(55.6)$ & $7(25.9)$ & $5(18.5)$ & $27(33.8)$ & \\
\hline \multirow[t]{2}{*}{ Side } & Right & $19(55.9)$ & $11(32.4)$ & $4(11.8)$ & $34(42.5)$ & 0.101 \\
\hline & Left & $16(34.8)$ & $17(37.0)$ & $13(28.3)$ & $46(57.5)$ & \\
\hline \multirow[t]{3}{*}{ Site (arch) } & Maxilla & $13(54.2)$ & $7(29.2)$ & 4 (16.7) & $24(30.0)$ & 0.135 \\
\hline & Mandible & $8(30.8)$ & $14(53.8)$ & $4(15.4)$ & $26(32.5)$ & \\
\hline & Both arches & $14(46.7)$ & $7(23.3)$ & $9(30.0)$ & $30(37.5)$ & \\
\hline \multirow{6}{*}{$\begin{array}{l}\text { Presence of occlusal inter- } \\
\text { ferences during mandibular } \\
\text { movements }\end{array}$} & No interferences & $2(33.3)$ & $2(33.3)$ & $2(33.3)$ & $6(7.5)$ & 0.345 \\
\hline & $\mathrm{RCP}$ & $6(33.3)$ & $9(50.0)$ & $3(16.7)$ & $18(22.5)$ & \\
\hline & PRO & $8(72.8)$ & $2(18.2)$ & $1(9.1)$ & $11(13.6)$ & \\
\hline & WS & $7(31.8)$ & $7(31.8)$ & $8(36.4)$ & $22(27.2)$ & \\
\hline & NWS & $5(45.5)$ & $5(45.5)$ & $1(9.1)$ & $11(13.6)$ & \\
\hline & More than one & $7(58.3)$ & $3(25.0)$ & $2(16.7)$ & $12(15.0)$ & \\
\hline \multirow{6}{*}{$\begin{array}{l}\text { Status of supraerupted and } \\
\text { opposing arches }\end{array}$} & No changes & $7(100)$ & $00(0.00)$ & $00(0.00)$ & $7(8.8)$ & $>0.001^{*}$ \\
\hline & $\begin{array}{l}\text { Buccolingual displacement of } \\
\text { supraerupted teeth }\end{array}$ & $14(73.7)$ & $4(21.1)$ & $1(5.3)$ & $19(23.8)$ & \\
\hline & $\begin{array}{l}\text { Presence of tilting or tipping in } \\
\text { mesial or distal of edentulous area }\end{array}$ & $9(45.0)$ & $11(55.0)$ & $00(0.00)$ & $20(25.0)$ & \\
\hline & Presence of occlusal wear & $5(31.3)$ & $10(62.5)$ & $1(6.3)$ & $16(20.0)$ & \\
\hline & Presence of open contact & $00(0.00)$ & $2(20.0)$ & $8(80.0)$ & $10(12.5)$ & \\
\hline & More than one & $00(0.00)$ & $1(12.5)$ & $7(78.5)$ & $8(10.0)$ & \\
\hline
\end{tabular}

*Significant differences

(33.8\%) maxillary and mandibular teeth, respectively. The numbers and percentages of mandibular molars [27(33.8\%)] were higher than those of maxillary molars [23(28.8\%)] (Table 3).

In the comparison of the amount of supraeruption $(\mathrm{mm})$ between the data collected from SCs and PRs in relation to the tooth and arch type (Fig. 2), no considerable differences in values had been recorded between the SC and PR except in one case for each of maxillary premolars, molars, and mandibular premolars; all values were observed in the $0.7-1.2 \mathrm{~mm}$ supraeruption subgroup. No significant differences were detected between 
Table 3: Frequency and percentage of variables in relation to supraerupted tooth type [Chi-square or Fisher's exact test ( $n=80)$ ]

\begin{tabular}{|c|c|c|c|c|c|c|}
\hline Variable & Age groups & $\begin{array}{c}\text { Maxilla } \\
\mathrm{N} \%\end{array}$ & $\begin{array}{l}\text { Mandibula } \\
\quad \text { N\% }\end{array}$ & $\begin{array}{c}\text { Both arches } \\
\quad \text { N\% }\end{array}$ & $\begin{array}{l}\text { Total } \\
\mathrm{N} \%\end{array}$ & $p$ values \\
\hline \multirow[t]{3}{*}{ Age } & $18-32$ & $13(54.2)$ & $8(30.8)$ & $14(46.7)$ & $35(43.7)$ & 0.124 \\
\hline & $33-47$ & $7(29.2)$ & $14(53.8)$ & $7(23.3)$ & $28(35.0)$ & \\
\hline & $>47$ & $4(16.7)$ & $4(15.4)$ & $9(30.0)$ & $17(21.3)$ & \\
\hline \multirow[t]{2}{*}{ Years since teeth loss } & $3-5$ year & $16(66.7)$ & $18(69.2)$ & $24(80.0)$ & $58(72.5)$ & 0.598 \\
\hline & $>5$ years & $8(33.3)$ & $8(30.8)$ & $6(20.0)$ & $22(27.5)$ & \\
\hline \multirow[t]{4}{*}{ Causes of teeth loss } & Periodontal disease & $4(16.7)$ & $1(3.8)$ & $1(3.3)$ & $6(7.5)$ & 0.145 \\
\hline & Dental caries & $13(54.2)$ & $23(88.5)$ & $18(60.0)$ & $54(67.5)$ & \\
\hline & Failed RCT & $5(20.8)$ & $2(7.7)$ & $7(23.3)$ & $14(17.5)$ & \\
\hline & Others & $2(8.3)$ & $0(00.0)$ & $4(13.3)$ & $6(7.5)$ & \\
\hline \multirow[t]{2}{*}{ Side } & Right & $10(41.7)$ & $14(53.8)$ & $10(33.3)$ & $34(42.5)$ & 0.484 \\
\hline & Left & $14(58.3)$ & $12(46.2)$ & $20(66.7)$ & $46(57.5)$ & \\
\hline \multirow[t]{4}{*}{ Tooth type } & Maxillary premolars & $5(20.8)$ & $1(3.8)$ & $6(20.0)$ & $12(15.0)$ & $0.000^{*}$ \\
\hline & Maxillary molars & $16(66.7)$ & $1(3.8)$ & $6(20.0)$ & $23(28.8)$ & \\
\hline & Mandibular premolars & $1(4.2)$ & $11(42.3)$ & $6(20.0)$ & $18(22.5)$ & \\
\hline & Mandibular molars & $2(8.3)$ & $13(50.0)$ & $12(40.0)$ & $27(33.8)$ & \\
\hline \multirow{6}{*}{$\begin{array}{l}\text { Presence of occlusal inter- } \\
\text { ferences during mandibular } \\
\text { movements: }\end{array}$} & No interferences & $4(16.7)$ & $1(3.8)$ & $1(3.3)$ & $6(7.5)$ & 0.114 \\
\hline & $\mathrm{RCP}$ & $2(8.3)$ & $8(30.8)$ & $8(26.7)$ & $18(22.5)$ & \\
\hline & PRO & $7(29.2)$ & $3(11.5)$ & $1(3.3)$ & $11(13.8)$ & \\
\hline & WS & $5(20.8)$ & $6(23.1)$ & $11(36.7)$ & $22(27.5)$ & \\
\hline & NWS & $3(12.5)$ & $4(15.4)$ & $4(13.3)$ & $11(13.8)$ & \\
\hline & More than one & $3(12.5)$ & $4(15.4)$ & $5(16.7)$ & $12(15.0)$ & \\
\hline \multirow{6}{*}{$\begin{array}{l}\text { Status of supraerupted and } \\
\text { opposing arches }\end{array}$} & No changes & $2(8.3)$ & $1(3.8)$ & $4(13.3)$ & $7(8.8)$ & 0.705 \\
\hline & $\begin{array}{l}\text { Buccolingual displacement of } \\
\text { supraerupted teeth }\end{array}$ & $8(33.3)$ & $5(19.2)$ & $6(20.0)$ & $19(23.8)$ & \\
\hline & $\begin{array}{l}\text { Presence of tiltingor tipping in } \\
\text { mesial/distal of edentulous area }\end{array}$ & $3(12.5)$ & $8(30.8)$ & $9(30.0)$ & $20(25.0)$ & \\
\hline & Presenceofocclusal wear & $6(25.0)$ & $6(23.1)$ & $4(13.3)$ & $16(20.0)$ & \\
\hline & Presenceofopencontact & $3(12.5)$ & $4(15.4)$ & $3(10.0)$ & $10(12.5)$ & \\
\hline & More than one & $2(8.3)$ & $2(7.7)$ & $4(13.3)$ & $8(10.0)$ & \\
\hline
\end{tabular}

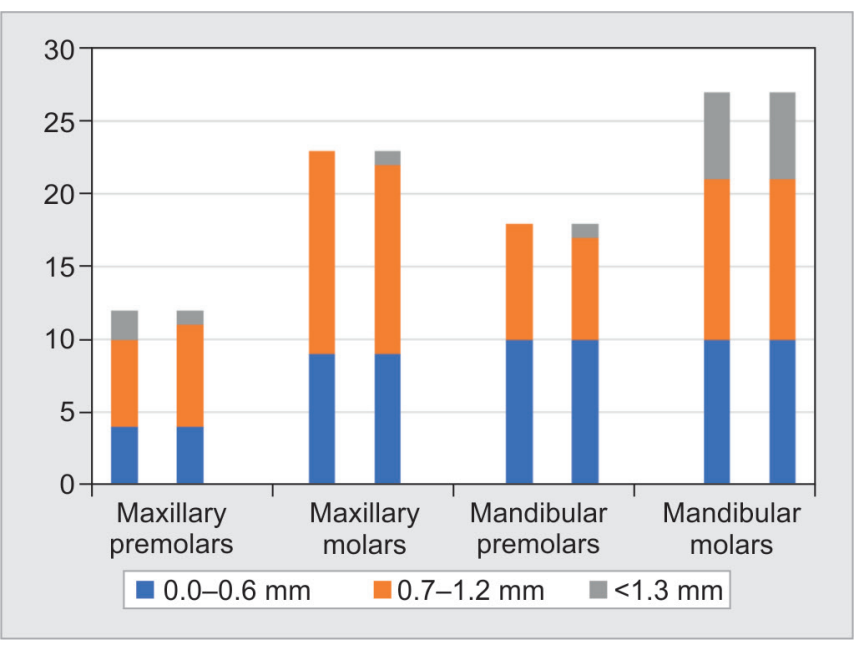

Fig. 2: Comparison of supraeruption ( $\mathrm{mm}$ ) observed from SCs and PRs

the values of supraerupted teeth in both arches and toothtypes. The recorded $p$-values were 0.051 and 0.131 for SCs and PRs, respectively.
Table 4: Intraexaminer agreement (Kappa test)

\begin{tabular}{lccc}
\hline $\begin{array}{l}\text { Type of occlusal } \\
\text { interference }\end{array}$ & Kappascore & $\begin{array}{c}\text { 95\% confidence } \\
\text { strength of interval } \\
\text { agreement }\end{array}$ & $\begin{array}{c}\text { Strength of } \\
\text { agreement }\end{array}$ \\
\hline RCP & 0.89 & $0.7-1.2$ & Very good \\
PRO & 0.71 & $0.6-1.2$ & Moderate \\
WS & 0.89 & $0.7-1.2$ & Very good \\
NWS & 0.61 & $0.1-1.3$ & Good \\
\hline
\end{tabular}

Table 4 shows the assessment of intraclinical examiner reliability in the presence of occlusal interferences during different mandibular movements using Kappa test scores for nominal data. The findings reveal the incidence of occlusal interferences in this study and the level of agreement was determined by the same clinical examiner in two separate examination times. Kappa test scores for all types of occlusal interference subgroups ranged from very good (RCP and WS) to moderate (PRO) and good (NWS).

The assessment was performed on the interclass correlation coefficient for the measurement of supraeruption $(\mathrm{mm})$ on the SCs and PRs. The intraexaminer reliabilities were determined by drawing a Bland-Altman plot 7 for continuous data. The two measurements 


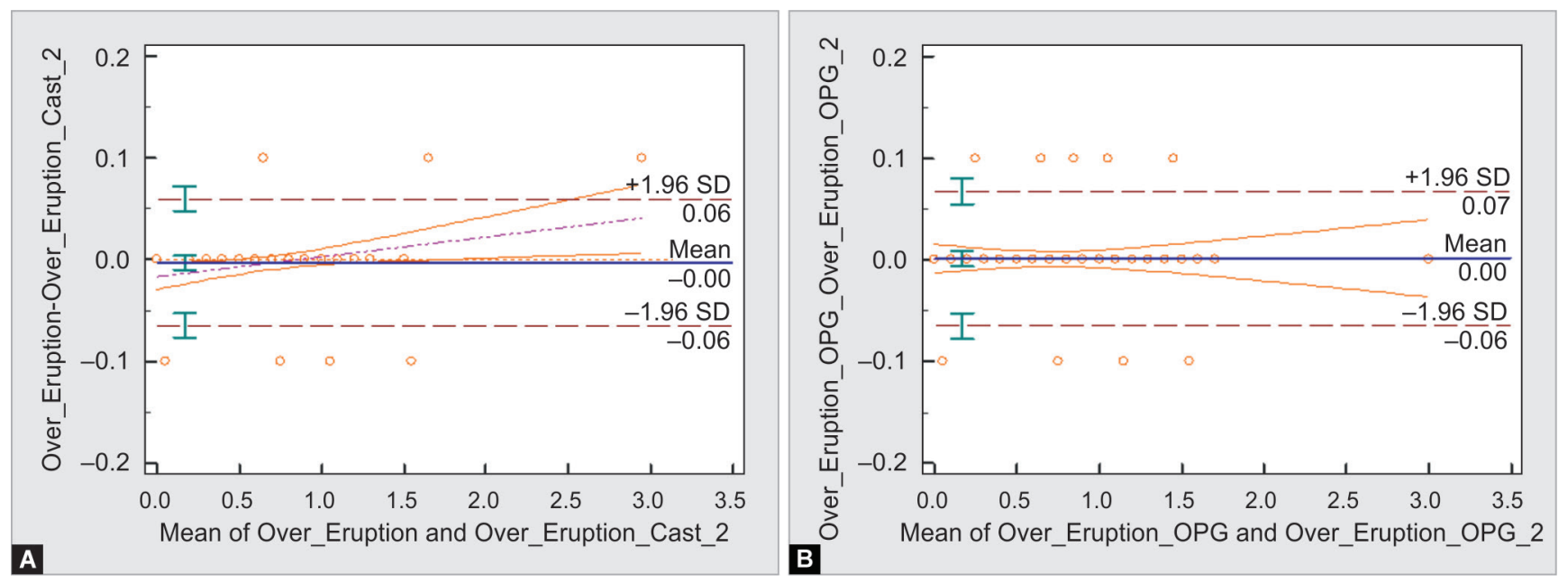

Figs $3 \mathrm{~A}$ and B: Bland-Altman plot demonstrating intraexaminer agreement for SCs and PRs, respectively

fell between the $95 \%$ and $99 \%$ confidence interval bands for the SCs and PRs (Fig. 3).

\section{Discussion}

Nonreplacement of posterior teeth in both arches could result in malocclusion and TMJ disorders, which may disrupt the appropriate foundation of stomatognathic stability if left unattended. ${ }^{3}$ Prosthodontic treatments in the presence of supraerupted teeth should be performed based on the indication and need in the presence of slight TMJ dysfunction. ${ }^{26}$ The literature recommends the use of positioning devices and prosthodontic measures to recapture the TMJ-complaining patients because of the favorable, long-term results achieved after using simpler methods. ${ }^{13,26}$ Following this trend, Matsuda et al. ${ }^{27}$ and Livas et al. ${ }^{28}$ observed that the amount of supraeruption inpatients who replaced their missing teeth with removable partial denturesor sectional retainers is considerably higher compared with those whose teeth were not opposed by any prosthesis. This comparative study aimed to measure and compare the amount of supraeruption of teeth from SCs and PRs, to assess the presence of occlusal interferences in patients with supraerupted teeth, and to record the tooth status in the adjacent or opposed arch of the extraction areas. The overall values of supraerupted teeth $(\mathrm{mm})$ showed a notably slight variance among the examined subgroups of SCs and PRs in terms of age groups and different types of teeth without any significant differences (Fig. 3). The first hypothesis was accepted, given that no significant difference was observed in the values of supraerupted teeth from SCs or/and PRs. In contrast to the supraeruption values from SCs and PRs, an occlusal interference was present, and tilting or drifting into tooth position after extraction had been documented in most of the participants.

Numerous parameters were involved in the descriptive statistics of this comparative study. First, the mean age \pm SD of subjects in the current study was $36.988 \pm 11.480$ years, which was less than that in the work of Craddock et al. ${ }^{1}$ in which the mean age \pm SD of participants was $50.9 \pm$ SD 13.9 years. Second, the mean values of supraeruption without antagonizing among participants recorded in this study reached $0.1-3.00 \mathrm{~mm}$ for the $\mathrm{SCs}$ and PRs. These values agree with those registered by Craddock et al. ${ }^{5}$ and Fagin et al., ${ }^{19}$ who recorded a supraeruption range between $0.0 \mathrm{~mm}$ and $3.99 \mathrm{~mm}$ with an average of 1.68 to $2 \mathrm{~mm}$ for SC, and that by Kim et al., ${ }^{25}$ who recorded a value $2.0 \mathrm{~mm}$ from the PRs of supraerupted teeth. However, Craddock and Youngson ${ }^{1}$ recorded slightly higher supraerupted tooth values between 0.5 $\mathrm{mm}$ and $5.4 \mathrm{~mm}$. For teeth without supraeruption, the frequencies were $6(7.5 \%)$ and 4 (5.0\%) for the SCs and PRs, respectively, and they were considerably lower compared with those in the work of Craddock and Youngson, ${ }^{1}$ who observed that $17 \%$ of their samples showed no supraeruption. Third, the damage of occlusal and interdental contact not only occurs in relation to complete tooth loss. This condition may also occur following dental caries, tooth fracture, loss or wear of either restorations, or tooth structures. ${ }^{17}$ Dental caries is the most common cause of tooth loss among patients in Jazan subpopulation, coinciding with the findings of Gossadi et al. ${ }^{22}$ and Noman et al., ${ }^{29}$ who concluded that dental caries accounted highest for the causes of tooth loss in southern SA (Jazan region) and adjacent countries. Fourth, in relation to the site of supraerupted teeth, contrary to the previous findings, 5,25 who mentioned that supraeruption was statistically higher in the maxillary arch, this study outcome demonstrated a higher number of supraerupted teeth in the mandibular arches, as also reported by Craddock and Youngson. ${ }^{1}$ Al Moaleem ${ }^{30}$ in 2007 concluded that mandibular teeth were the most extracted teeth among subjects from Jazan City, supporting the similarity between our findings and those observed by Craddock et al. ${ }^{18}$ Additionally, the supraeruption on the left side was slightly higher [46(57.5\%)] than the right side. Finally, supraeruption was most common in the molar teeth, as also seen by Gossadi et al. ${ }^{22}$ and AI Moaleem; ${ }^{30}$ however, Craddock et al. ${ }^{5}$ concluded that premolars are the most supraerupted teeth.

Supraeruption is defined as a measurement of exceeding zero from the cusp tip of the posterior teeth behind the canine. ' In the present study, the total mean values of supraeruption ranged between $0.0 \mathrm{~mm}$ and $3.0 \mathrm{~mm}$, with the highest percentages observed in the 18-32-year-old age group and among molars in either maxillary or mandibular arches (Fig. 2; Tables 2 and 3), but showed no significant difference between the SCs and PRs. The values and findings matched the mean values recorded by previous researchers, ${ }^{5,19,25}$ who observed values ranging between 
$1.86 \mathrm{~mm}$ and $2 \mathrm{~mm}$ among younger-age patients. In addition, no substantial differences were detected between individual SCs and their respected PRs, and this result could be explained by the small sample size and low number of years passed after extractions (mostly under 35 years). Mandibular molars were the most commontype of teeth recorded in the SCs and PRs [27(33.8\%)] compared with other types of teeth, including maxillary molar and premolars or mandibular premolars. This result disagrees with the findings of Craddock et al. ${ }^{5}$ who observed maxillary premolars as the most supraerupted teeth but coincides with other study ${ }^{1}$ who counted $61.8 \%$ of supraerupted teeth in the mandibular arch.

Results in Table 3 show that the highest values and percentage of supraeruption ranged between $0.7 \mathrm{~mm}$ and $1.2 \mathrm{~mm}$ for the SCs and PRs and near to those mentioned in other studies. Craddock and Youngson ${ }^{1}$ mentioned that approximately $32 \%$ of the teeth had supraeruption in excess of $2 \mathrm{~mm}$ and $6.7 \%$ in excess of $3 \mathrm{~mm}$; one tooth demonstrated a supraeruption of $5.39 \mathrm{~mm}$. Few studies ${ }^{19,20}$ identified a supraeruption greater than $2 \mathrm{~mm}$ in $24 \%$ of unopposed teeth, with $18 \%$ having no demonstrable supraeruption. Thus, $82 \%$ of the teeth demonstrated supraeruption to a certain extent, which in terms of restoration could be clinically significant.

Craddock et al. ${ }^{18}$ demonstrated typical findings similar to the present study, which could be due to the similarities in methodology, that is, using one examiner at different times, and age of participants in both studies. Figure 3 reveals that the average intraexaminer reliability in the measurement of supraeruption was very good for RCP and WS interferences, whereas it was good or moderate for NWS and PRO movements based on the Kappa test for all occlusal interferences during mandibular movements. Comparable findings were confirmed by Craddock and Youngson and Craddock et al. ${ }^{1,18}$

Unopposed posterior teeth are more likely to be involved in RCP contacts or interferences than their matched controls. ${ }^{18}$ The initial RCP contacts are linked with the values/extent of supraeruption of the unopposed teeth. The RCP wasthe second most occlusal interference in the current study and accounted for 18 cases; whereas Craddock and Youngson ${ }^{1,31}$ observed 51\% RCP among their subjects. No associations between patient or tooth factors were found for NWS interferences; the only association found for these interferences was with PRO on the extraction sites. ${ }^{18}$ WS interferences were associated with the tipping of teeth mesial to the site of tooth loss. The current study outcome shows that WS interference was the most common type of occlusal interference in 22 cases (27.2\%). A value near this percentage was recorded among the subjects in the study of Craddock. ${ }^{18}$ The presence and position of the teeth distal to the extraction sites were significant when modeling PRO interferences. PRO interferences are prevalent onsites with bounded tooth loss as shown in the samples examined by Craddock and Youngson"; however, a limited number of such cases were noted among our findings. Such results could be due to the younger age of our participants and the shorter period of extractions compared with those of previous studies.

Practitioners should understand the associated tooth movement following extraction to provide the most appropriate care for their patients. ${ }^{4}$ Thus, treatment planning must be supported by the guidance of current evidence and should include the possible scale needed to be appreciated by patients and practitioners. ${ }^{3,26}$ Significant differences were detected in the supraerupted teeth relative to the age groups and tooth type similar to Craddock and
Youngson. ${ }^{1}$ In the current study, among the different age groups, the types of supraerupted teeth (Tables 2 and 3), buccolingual displacement of supraerupted teeth, and the presence of tilting or tipping in mesial or distal of edentulous area were the most common changes, with 23.8 and $25 \%$ in the supraerupted and opposing arches, respectively, with a significant difference observed among all age groups and type of teeth. This finding could be explained by bone density and the complex activity of the stomatological structure of the participants during the survival period, whereas Craddock et al. ${ }^{17}$ demonstrated no clinically significant difference. This finding can be explained by the equilibrium theory, which states that a force similar to that used for the maintenance of buccolingual position exists in the unopposed teeth. ${ }^{32}$

Considerable subjective evidence is available on tooth positional deviations following the loss of an adjacent tooth, but limited literature exists. Teeth adjacent to the site of tooth loss may undergo nonvertical movements, whereas teeth mesial to the loss site undergo tipping distally. The degree of tipping increases in the maxillary teeth and in subjects with a cusp-tocusp buccal occlusion. ${ }^{17}$ This result disagrees with our conclusions (Table 4), in which mandibular teeth were recorded in 14 cases compared with the 6 cases noted in maxillary teeth. Craddock et al. ${ }^{17}$ stated that rotation of the teeth distal to the extraction site was greater in the maxilla, and dissimilar findings were observed for mandibular and maxillary teeth registered in this comparative study [14 (17.5\%) and 6 (7.5\%), respectively]. Craddock et al..$^{5}$ mentioned that relative wearing of teeth is associated with the increase in age and more prevalent in unopposed mandibular teeth; this condition is inevident in our samples, which recorded 16 (20.0\%) cases among the different age groups and types of teeth; this finding may be due tothe inclusion of participants over 47 years, which accounted for $17(21.2 \%)$ of the total sample size. No occlusal changes were represented by seven samples, coinciding with the findings of Craddock et al. ${ }^{5,17}$

Assessment of the intraexaminer reliability for checking the supraeruption by Bland-Altmanplots and Kappa test score for the agreement was registered $95-97 \%$ confidence interval band as shown by the values recorded from SCs and PRs (Fig. 3) and Kappa test scores (Table 4). A good and satisfactory overall reliability was observed in this study.

The minor drawbacks of this study were mostly due to the small number of clinical cases. In addition, the measurements of supraeruption were only performed in the occlusal direction. The use of recent materials and equipment for interocclusal interferences registrations and cone-beam computed tomography for measurement of supraeruption is recommended. Finally, studies involving larger sample sizes would lead to more expressive outcomes.

\section{Conclusion}

The following conclusions were drawn from the results of the current comparative study. No significant differences were observed in the supraeruption values between the tooth type among different subgroups of SCs and PRs. While, significant differences were recorded between the types and sites of teeth, with higher numbers and ratio noted in molar teeth, mandibular arch, and with a younger-age group. The RCP and WS interferences were the most recorded occlusal interferences. Buccolingual displacement, tilting, and tipping in mesial or distal of edentulous area were the 
most noticeable occlusal tooth movements. The methodology used in the study can be justified based on good relation of the intraexaminer reliability using Kappa scoresand good confidence interval band based on Bland-Altman plot.

\section{References}

1. Craddock HL, Youngson CC. A study of the incidence of overeruption and occlusal interferences in unopposed posterior teeth. Br Dent $J$ 2004;196(6):341-348; discussion 37. DOI: 10.1038/sj.bdj.4811082.

2. Al Ahmari NM, Aldhalail MA, Abidi NH, et al. Techniques for management of supraerupted teeth prior to prosthetic treatment: updated review. Biosci Biotechnol Res Commun 2020;13(1):261-273. DOI: $10.21786 / \mathrm{bbrc} / 13.1 / 43$

3. Gupta S, Pratibha P, Bhat K, et al. Non-replaced mandibular first molars and temporomandibular joint dysfunction. Nepal J Med Sci 2014;3(1):57-62. DOI: 10.3126/njms.v3i1.10360.

4. Craddock HL. Consequences of tooth loss: 2. Dentist considerations-restorative problems and implications. Dent Update 2010;37(1):28-32. DOI: 10.12968/denu.2010.37.1.28.

5. Craddock HL, Youngson CC, Manogue M, et al. Occlusal changes following posterior tooth loss in adults. Part 1: a study of clinical parameters associated with the extent and type of supraeruption in unopposed posterior teeth. J Prosthodont 2007;16(6):485-494. DOI: 10.1111/j.1532-849X.2007.00212.x.

6. Mahoorkar S, Puranik SN, Moldi A, et al. Management of supraerupted posterior teeth. Int J Dent Clin 2010;2(3).

7. Basutkar N, Wali O,Adbul QadeerAhmad S, et al. Management of severely supra-erupted teeth with endocrown: case report. Acta Sci Dent Sci 2018;2(9).

8. Prakash P, Nishanth K, Jasani N, et al. Intrusion of overerupted molars using miniscrews and TMA spring: a case report. IJSS 2014;1(1):4.

9. Salazar G, Serrano AF, Mazzey GO. Intrusion of an overerupted maxillary molar with orthodontic mini implants for implant restorative purposes. J Int Oral Health 2018;10(1):44. DOI: 10.4103/ jioh.jioh_236_17.

10. Patil SA, Kulkarni S, Thakur S, et al. Crown lengthening procedure following intentional endodontic therapy for correction of supraerupted posterior teeth: case series with long-term follow-up. J Indian Soc Periodontol 2016;20(1):103. DOI: 10.4103/0972-124X.175176.

11. Tiago CM, Previdente L, Nouer PRA. Molar intrusion with orthodontic mini-implants. RGO—Rev Gaúch Odontol 2016;64(3):327-332. DOI: 10.1590/1981-8637201600030000133274

12. Baeg S, On S, Lee J, et al. Posterior maxillary segmental osteotomy for management of insufficient intermaxillary vertical space and intermolar width discrepancy: a case report. Maxillofac Plast Reconstr Surg 2016;38(1):28. DOI: 10.1186/s40902-016-0074-0.

13. Djemal S, Bavisha K, Gilmour G. Management of a supra-erupted premolar: a case report. Dent Update 2004;31(4):220-222. DOI: 10.12968/denu.2004.31.4.220.

14. Marcus SE, Drury TF, Brown LJ, et al. Tooth retention and tooth loss in the permanent dentition of adults: United States, 1988-1991. J Dent Res 1996;75 Spec No:684-95. DOI: 10.1177/002203459607502S08.

15. Newman M, Takei H, Klokkevold P, et al. Newman and Carranza's clinical periodontology. Saunders; 2018.

16. Compagnon D, Woda A. Supraeruption of the unopposed maxillary first molar. J Prosthet Dent 1991;66(1):29-34. DOI: 10.1016/00223913(91)90347-y.
17. Craddock HL, Youngson CC, Manogue $\mathrm{M}$, et al. Occlusal changes following posterior tooth loss in adults. Part 2. Clinical parameters associated with movement of teeth adjacent to the site of posterior tooth loss. J Prosthodont 2007;16(6):495-501. DOI: 10.1111/j.1532849X.2007.00223.x.

18. Craddock HL. Occlusal changes following posterior tooth loss in adults. Part 3. A study of clinical parameters associated with the presence of occlusal interferences following posterior tooth loss. J Prosthodont 2008;17(1):25-30. DOI: 10.1111/j.1532849X.2007.00239.x.

19. Faggion CM, Jr., Giannakopoulos NN, Listl S. How strong is the evidence for the need to restore posterior bounded edentulous spaces in adults? Grading the quality of evidence and the strength of recommendations. J Dent 2011;39(2):108-116. DOI: 10.1016/j. jdent.2010.11.002.

20. Kiliaridis S, Lyka I, Friede H, et al. Vertical position, rotation, and tipping of molars without antagonists. Int J Prosthodont 2000;13(6):480-486.

21. McCaul LK, Jenkins WM, Kay EJ. The reasons for extraction of permanent teeth in Scotland: a 15-year follow-up study. Br Dent J 2001;190(12):658-662. DOI: 10.1038/sj.bdj.4801068.

22. Gossadi $\mathrm{Yl}$, Nahari $\mathrm{H}$, Kinani $\mathrm{H}$, et al. Reasons for permanent teeth extraction in Jizan region of Saudi Arabia. IOSR-JDMS 2015;14(1):8689. DOI: 10.9790/0853-14178689.

23. Meshni AA, Al Moaleem MM, Mattoo KA, et al. Radiographic evaluation of post-core restorations fabricated by dental students at Jazan University. J Contemp Dent Pract 2018;19(1):66-72. DOI: 10.5005/jp-journals-10024-2213.

24. Glossary of Prosthodontic Terms NE, GPT-9. The Academy of Prosthodontics Foundation. J Prosthet Dent 2017;117(5S):e1-e105. DOI: 10.1016/j.prosdent.2016.12.001.

25. Kim YK, Ahn KJ, Yun PY, et al. The clinical prognosis of implants that are placed against super-erupted opposing dentition. J Korean Assoc Oral Maxillofac Surg 2016;42(3):139-143. DOI: 10.5125/ jkaoms.2016.42.3.139.

26. De Boever JA, Carlsson GE, Klineberg IJ. Need for occlusal therapy and prosthodontic treatment in the management of temporomandibular disorders. Part II: Tooth loss and prosthodontic treatment. J Oral Rehabil 2000;27(8):647-659. DOI: 10.1046/j.13652842.2000.00623.x.

27. Matsuda K, Miyashita Y, Ikebe K, et al. Overeruption of teeth opposing removable partial dentures: a preliminary study. Int J Prosthodont 2014;27(5):475-476. DOI: 10.11607/ijp.4006.

28. Livas C, Halazonetis DJ, Booij JW, et al. Does fixed retention prevent overeruption of unopposed mandibular second molars in maxillary first molar extraction cases? Prog Orthod 2016;17(1):6. DOI: 10.1186/ s40510-016-0119-z.

29. Noman NA, Aladimi AA, Alkadasi BA, et al. Social habits and other risk factors that cause tooth loss: an associative study conducted in Taiz Governorate, Yemen. J Contemp Dent Pract 2019;20(4):429.

30. Al Moaleem M. Patterns of partial edentulism and its relation to khat chewing in Jazan population-a survey study. J Clin Diagn Res 2017;11(3):ZC55. DOI: 10.7860/JCDR/2017/23604.9577.

31. Craddock HL, Youngson CC. Eruptive tooth movement--the current state of knowledge. Br Dent J 2004;197(7):385-391. DOI: 10.1038/ sj.bdj.4811712.

32. Proffit WR. Equilibrium theory revisited: factors influencing position of the teeth. Angle Orthod 1978;48(3):175-186. DOI: 10.1043/0003-3219(1978)048<0175:ETRFIP > 2.0.CO;2. 


\section{Appendix 1}

\section{CLINICAL AND RADIOGRAPHICAL MEASUREMENTS OF SUPRAERUPTION INCIDENCE AND OCCLUSAL INTERFERENCES IN UNOPPOSED POSTERIOR TEETH}

File \# Serial \#

Part I-Personal and Demographic Data

- Age: $18-32,33-42$, and $>43$ years old

- History of extraction: 3-5 and $>5$ years

- Causes of extraction: periodontal, caries, failed RCT; others

\section{Part 2-Clinical Examination Data}

- Supraerupted tooth/teeth: maxillary premolars or molars; mandibular premolars or molars

- Supraerupted side: right or left

- Supraerupted site: maxilla, mandibula, or both

- Presence of occlusal interferences during mandibular movements ("yes"or "no"): No, RCP, PRO, WS, and NWS

Part 3-Diagnostic Cast Analysis Data

- Amount of supraeruption measured from cast: $0.1-0.6,0.7-1.2$, and $>1.3 \mathrm{~mm}$

- Status of the supraerupted and opposed tooth/teeth answerable by "yes" or "no":

- No occlusal changes;

- Buccolingual displacement of supraerupted teeth;

- Presence of tilting or tipping in mesial or distal of edentulous area;

- Presence of occlusal wear;

- Presence of open contact;

- More than one.

Part 4-Radiographic Analysis Data

Amount of supraeruption measured from PR: 0.1-0.6, 0.7-1.2, and $>1.3 \mathrm{~mm}$. 